\title{
Pott's spine in an infant: a diagnostic challenge
}

\author{
*Manas Kumar Mahapatra ${ }^{1}$, Devdeep Mukherjee ${ }^{1}$, Ritabrata Kundu ${ }^{1}$, Joydeep Das ${ }^{1}$
}

Sri Lanka Journal of Child Health, 2017; 46(2): 184-186

DOI: http://dx.doi.org/10.4038/sljch.v46i2.8280

(Key words: Tuberculosis, Pott's spine, pyrexia of unknown origin, infant)

\section{Introduction}

Spinal tuberculosis (TB) is uncommon in children, more so in infancy ${ }^{1,2}$. We report an 8 month old child who presented with pyrexia of unknown origin and was diagnosed to have spinal TB.

\section{Case report}

An 8 month old male baby was referred to our hospital with fever (101-102 $\mathrm{F}$, 6-8 hourly /day.) for last one month. Baby was born at term of a nonconsanguineous marriage, through normal vaginal delivery with no significant antenatal or perinatal history. He had been vaccinated as per national immunization schedule. Weight gain was satisfactory (birth weight $2.3 \mathrm{~kg}$, admission weight $7.5 \mathrm{~kg}$ ). There was no history of contact with tuberculosis (TB). On examination, the baby was extremely irritable and febrile with moderate pallor. He had a respiratory rate of $23 / \mathrm{min}$ (equal air entry bilaterally), a heart rate of $128 / \mathrm{min}$ and a blood pressure of $66 / 42 \mathrm{~mm} \mathrm{Hg}$. His liver and spleen were palpable $2 \mathrm{~cm}$ and $1 \mathrm{~cm}$ below the costal margin respectively. Other system examination was normal. Investigations done are shown in Table 1.

Table 1: Summary of investigations performed

\begin{tabular}{|l|c|c|c|}
\hline \multicolumn{1}{|c|}{ Investigation } & Pre-admission & At admission & At 1 month follow up \\
\hline $\mathrm{Hb}(\mathrm{g} / \mathrm{dl})$ & 6.9 & 7.2 & 8.1 \\
\hline Total leucocyte count (/cu mm) & 3,800 & 4,400 & 7,600 \\
\hline Differential count & N31, L66, M2, E1 & N36, L58, M4, E2 & N33, L62, M4, E1 \\
\hline Platelet count(/cu mm) & 260,000 & 647,000 & 362,000 \\
\hline Peripheral blood smear & Normal & Normal & \\
\hline Malaria (slide and antigen) & Negative & Negative & \\
\hline Erythrocyte sedimentation rate (mm st $^{\text {st }}$ hour) & 105 & 113 & 38 \\
\hline C-reactive protein $(\mathrm{N}<5)$ & 57.2 & 62 & 4.2 \\
\hline Blood culture & No growth & No growth & \\
\hline Urine full report & Normal & Normal & \\
\hline Urine culture & No growth & No growth & \\
\hline Widal test & Negative & Negative & \\
\hline Renal function tests & Normal & Normal & \\
\hline Liver function tests & Normal & Normal & \\
\hline Chest X ray & Normal & Normal & \\
\hline Ultrasonography abdomen & Normal & Normal & \\
\hline Gastric lavage for acid fast bacilli & Negative & & \\
\hline Iron (mcg/dl) & & 12 & \\
\hline Ferritin (ng/ml) & & 379 (Normal) & \\
\hline Procalcitonin (ng/ml) & & 0.42 (negative) & \\
\hline
\end{tabular}

${ }^{1}$ Institute of Child Health, Kolkata, India

*Correspondence: manaskrmahapatra@gmail.com

(Received on 06 February 2016: Accepted after revision on 17 March 2016)

The authors declare that there are no conflicts of interest

Personal funding was used for this project.

Open Access Article published under the Creative

Commons Attribution CC-BY (CC) (i)
He was treated with inj. cefotaxime, piperacillin, tazobactum, amikacin and azithromycin before admission. However, fever persisted throughout this period along with a persistently high erythrocyte sedimentation rate (ESR) and C-reactive protein (CRP). Blood and urine cultures were negative. A lumbar puncture revealed 50 cells (all lymphocytes), protein $96 \mathrm{mg} / \mathrm{dl}$ and sugar $42 \mathrm{mg} / \mathrm{dl}$. Cerebrospinal fluid (CSF) staining and culture were negative for organisms. Mantoux test with 5TU gave an 
induration of $12 \mathrm{~mm}$. Gene Xpert from induced sputum was negative for TB. His HIV serology was negative. Immunoglobulin ( $\operatorname{Ig} \mathrm{A}, \operatorname{IgM}, \operatorname{IgG}$ ) profile was normal and he had normal CD4:CD8 ratio ruling out any evidence of underlying immunodeficiency.

As CSF and Mantoux were suggestive of TB, anti-TB therapy (ATT) was started with isoniazid, rifampicin, pyrazinamide and ethambutol (HRZE) with oral prednisolone. However, over the next 7 days, baby developed decreased mobility of both legs. Motor examination, which initially was normal, showed brisk knee and ankle jerks with ankle clonus. Magnetic resonance imaging (MRI) of brain and spine was planned. On the next day we found a swelling over dorso-lumbar spine (Figure 1a).

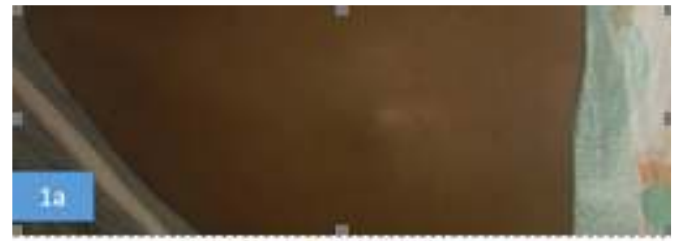

Figure 1a: Gibbus

MRI spine showed kyphosis of dorso-lumbar junction, features of spondylodiscitis involving the D12 and L1 vertebral bodies with compression over conus by bulging posterior surface of the vertebral bodies, with intra-medullary signal changes within the conus, possibly due to caries spine (Figure 1b).

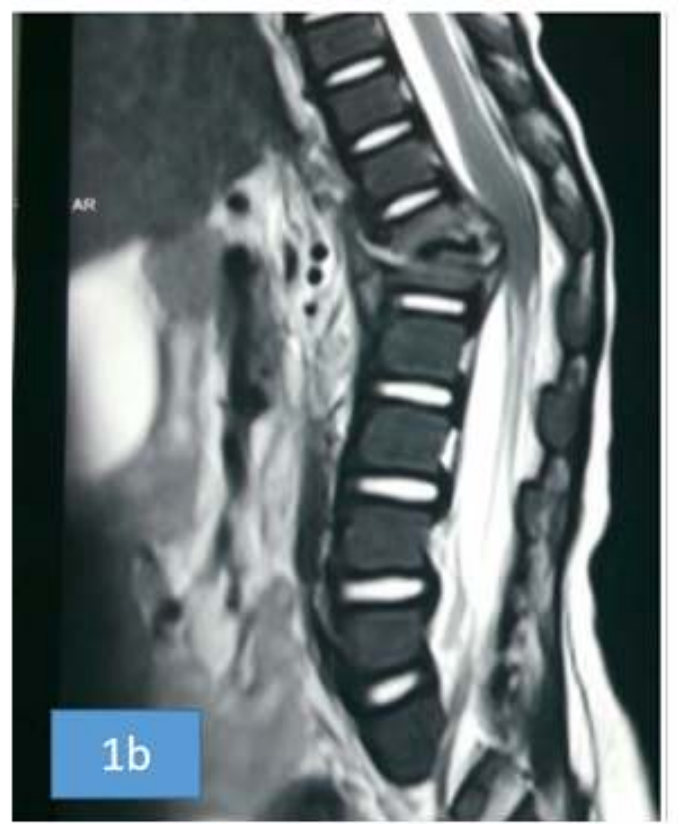

Figure 1b: MRI spine showing kyphosis of dorso -lumbar junction and features of spondylodiscitis invplving the $D 12$ and $L 1$ vertebral bodies
Spine at risk sign was assessed. Computed tomography (CT) guided fine needle aspiration biopsy revealed epithelioid cell granulomas suggestive of TB. Moulded brace was advised to restrict mobility of spine. Baby became afebrile after 12 days of ATT. In follow up, he was afebrile. Mobility of his lower limbs was normal. However, the gibbus persists even after 5 months. He has had a vertebral collapse (Figure 1c).

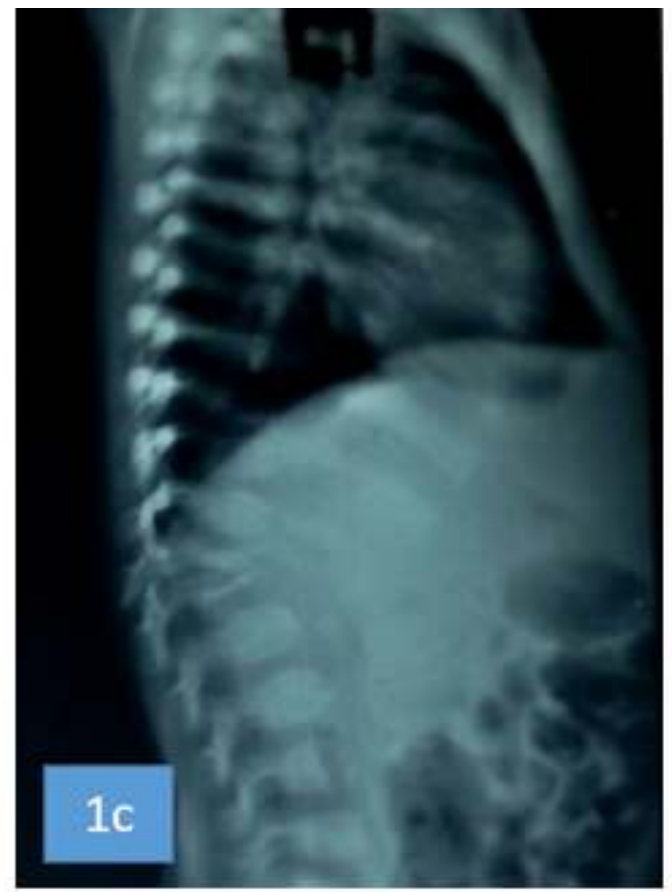

Figure lc: Vertebral collapse of Ll

$\mathrm{He}$ is undergoing regular follow up with the neurosurgeon at our institute. We plan to carry on a conservative approach with the brace for a further 6 months. Contact tracing did not reveal any family members or caregivers having TB.

\section{Discussion}

Lungs are the commonly affected organs in children with TB. Involvement of the spine is often insidious ${ }^{1}$. Skeletal TB is seen in approximately $10 \%$ of all patients with extra pulmonary involvement the spine being involved in 50\% followed by the hip and knee. Spinal TB is more common in children and young adults $^{2}$. However, there are very few case reports in infants ${ }^{1,3}$. Our child presented at 8 months of age and was diagnosed to have spinal involvement. Skeletal involvement usually occurs as a result of haematogenous spread from a primary focus, which we could not localize ${ }^{2}$. The age of presentation and failure to establish Cantwell's criteria, ruled out congenital TB in our case $\mathrm{c}^{4}$. 
Common sites of vertebral involvement are the central, antero-inferior and the paradiskal part. Vertebra plana can result due to collapse of the central part. Increased involvement of the central disk is possibly because of increased vascularity in younger patients ${ }^{2}$. Our case had a vertebral collapse with fusion of adjacent vertebra. Intervertebral disk space destruction leads to anterior wedging, which ultimately leads to gibbus as we saw in our patient ${ }^{2}$. Multiple vertebrae are usually involved as we had in our child (D12 and L1) ultimately leading to spinal deformities $^{1-3}$.

Apart from the constitutional symptoms, patients have pain, tenderness in affected region, restricted mobility of limbs, muscle spasm, gibbus and spinal deformity. It was difficult to assess for pain in our child. However brisk jerks in our patient can be explained by spinal cord compression ${ }^{2}$. He did not have any localized abscess. Spinal TB is uncommon in infancy as it takes more than 1 year to develop. Moreover, paraplegia or quadriplegia are less severe in infants and hence diagnosis gets delayed ${ }^{5}$. Pyrexia of unknown origin and sudden appearance of gibbus made us suspect spinal TB.

Radiological investigation remains the mainstay of diagnosis. MRI delineates the spread of disease and nerve involvement as we saw in our patient ${ }^{2}$. Neuroimaging guided needle biopsy is the gold standard for confirmation of diagnosis as performed for our patient ${ }^{2}$. He was started on ATT as per revised national TB programme guidelines (RNTCP) of $2 \mathrm{HRZE}+4 \mathrm{HR}$ as no separate guidelines for spinal TB exist.

At 5 months follow up, he is gaining weight. We are continuing with the moulded brace, which we plan to continue for a further period of 6 months. He can stand with support and can walk a few steps as well. Spinal TB is rare in infancy. Involvement of the spine/bones should be ruled out in any patient presenting with pyrexia of unknown origin. A high level of suspicion, early diagnosis and prompt treatment is needed to minimize the mortality and morbidity related to spinal $\mathrm{TB}$.

\section{References}

1. Kiymaz N, Yilmaz N, Demir O. Spinal cord compression from spinal tuberculosis in a child. Pediatric Neurosurgery 2006; 42(3): 180-2.

http://dx.doi.org/10.1159/000091864

PMid: 16636622

2. Garg RK, Somvanshi DS. Spinal tuberculosis: A review. Journal of Spinal Cord Medicine 2011; 34(5): 440-54.

http://dx.doi.org/10.1179/2045772311Y.000 0000023

PMid: 22118251 PMCid: PMC3184481

3. Tufan K, Dogulu F, Kardes O, Oztanir N, Baykaner MK. Dorsolumbar junction spinal tuberculosis in an infant: case report. Journal of Neurosurgery 2005; 102(4 Suppl.):431. http://dx.doi.org/10.3171/ped.2005.102.4.04 31

4. Cantwell MF, Shehab ZM, Costello AM, Sands L, Green WF, Ewing EP Jr et al. Brief report. Congenital tuberculosis. New England Journal of Medicine 1994; 330: 1051-4.

http://dx.doi.org/10.1056/NEJM1994041433 01505

PMid: 8127333

5. Santos FC, Nascimento AL, Lira LA, Lima JF, Montenegro Rde A, Montenegro LM et al; Bone tuberculosis: a case report on child. Rev Soc Bras Med Trop. 2013; 46(2):24951 ; http://dx.doi.org/10.1590/0037-8682-00102012

PMid: 23740070 